\title{
Short-wavelength undulatory extinction in quartz recording coseismic deformation in the middle crust - an experimental study
}

\author{
C. A. Trepmann ${ }^{1}$ and B. Stöckhert ${ }^{2}$ \\ ${ }^{1}$ Department of Earth and Environmental Sciences, Ludwig-Maximilians-Universität München, Munich, Germany \\ ${ }^{2}$ Institute of Geology, Mineralogy and Geophysics, Ruhr-Universität Bochum, Bochum, Germany \\ Correspondence to: C. A. Trepmann (claudia.trepmann@lmu.de)
}

Received: 20 March 2013 - Published in Solid Earth Discuss.: 8 April 2013

Revised: 3 July 2013 - Accepted: 9 July 2013 - Published: 4 September 2013

\begin{abstract}
Deformation experiments are carried out on natural vein quartz in a modified Griggs-type solid medium apparatus to explore the preservation potential of microfabrics created by crystal-plastic deformation at high stress, overprinted during subsequent creep at lower stress. A corresponding stress history is expected for the upper plastosphere, where fault slip during an earthquake causes quasiinstantaneous loading to high stress, followed by stress relaxation. The question is whether evidence of crystal-plastic deformation at high stress, hence an indicator of past seismic activity, can still be identified in the microstructure after overprint by creep at lower stresses. First, quartz samples are deformed at a temperature of $400^{\circ} \mathrm{C}$ and constant strain rate of $10^{-4} \mathrm{~s}^{-1}$ ("kick"), and then held at 900 to $1000^{\circ} \mathrm{C}$ at residual stress ("creep"). In quartz exclusively subject to high-stress deformation, lamellar domains of slightly differing crystallographic orientation (misorientation angle $<2^{\circ}$ ) and a few tens of micrometres wide occur. In the transmission electron microscope (TEM), these areas show a high density of tangled dislocations and cellular structures. After "kick and creep" experiments, pronounced short-wavelength undulatory extinction (SWUE) is observed in the polarization microscope. The wavelength of SWUE is up to $10 \mu \mathrm{m}$, with oscillatory misorientation of up to a few degrees. TEM inspection reveals domains with high density of dislocations and differing diffraction contrast bound by poorly ordered dislocation walls. Only zones with exceptional damage generated during high-stress deformation are replaced by small new grains with a diameter of about 10 to $20 \mu \mathrm{m}$, forming strings of recrystallized grains. For large original grains showing SWUE, the Schmid factor for basal $\langle a\rangle$ glide is found to be high. SWUE is taken to reflect high-stress crystal-plastic de-
\end{abstract}

formation, the modified microstructure being sufficiently stable to be recognized after subsequent creep as an indicator of past seismic activity.

\section{Introduction}

Seismic activity in the upper crust implies a cyclic stress history in the lower crust (e.g. Tse and Rice, 1986; BenZion and Rice, 1997; Ben-Zion and Lyakhovsky, 2006; Ellis and Stöckhert, 2004; Nüchter and Ellis, 2010). During a large earthquake (Scholz, 2002), coseismic stress relief in the schizosphere is concomitant with quasi-instantaneous loading in the underlying plastosphere (Fig. 1). Inversely, slow stress relaxation by creep in the deeper crust is concomitant with gradual reloading of the brittle fault above. The terms schizosphere and plastosphere were introduced by Scholz (2002). Schizosphere denotes the layer transected by coseismic rupture during a large earthquake. Rupture does not propagate into the underlying plastosphere. The boundary between these spheres is defined for the instant of a large earthquake only (Fig. 1). It lies at greater depth compared to the long-term brittle-viscous transition, which - for continental crust - is commonly associated with the onset of slow deformation by dislocation creep of quartz at temperatures around $300^{\circ} \mathrm{C}$ (e.g. Dunlap et al., 1997; Stöckhert et al., 1999; van Daalen et al., 1999; Hirth et al. 2001; Stipp et al., 2002). The seismogenic zone, where earthquakes nucleate along brittle faults, is confined to within the schizosphere (e.g. Scholz, 2002; Ben-Zion, 2008).

The effects of earthquake-related stress changes in the uppermost plastosphere, with quasi-instantaneous loading 


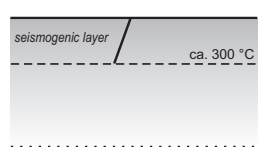

long term

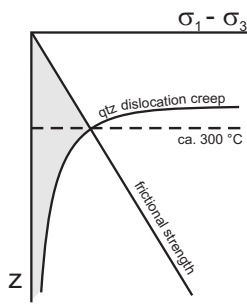

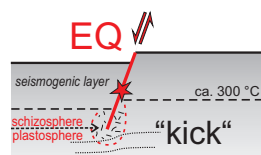

coseismic loading

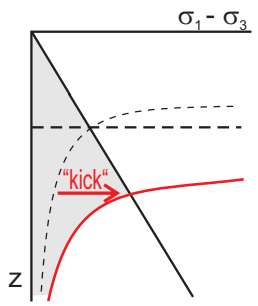

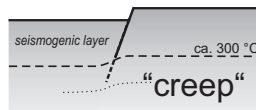

postseismic creep

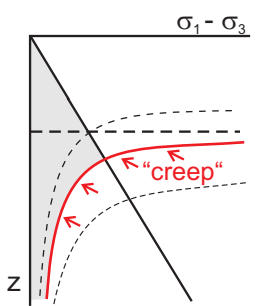

Fig. 1. Stress and strain rate changes during the seismic cycle, visualized by hypothetical crustal strength profiles (not to scale). Hypocentre is marked by asterisk. Around the lower termination of the downward propagating rupture plane of a large earthquake, i.e. at the boundary between schizosphere and plastosphere sensu Scholz (2002), quasi-instantaneous coseismic loading to high differential stress causes deformation of quartz in the low-temperature plasticity regime ("kick"). During subsequent stress relaxation and restoration of long-term state, quartz deforms by dislocation creep at decaying strain rate ("creep"), each stage of the earthquakerelated stress cycle leaving a characteristic microstructural imprint. In the present study, modification of microstructures acquired during the "kick" stage in the course of subsequent "creep" deformation is investigated in laboratory experiments.

leading to brittle and crystal-plastic deformation followed by a stage of creep at decaying stress, are identified in the record of exhumed metamorphic rocks (e.g. Küster and Stöckhert, 1999; Trepmann and Stöckhert, 2001; 2002; 2003). The natural microstructures provide insight into details of deformation processes on microscopic scale, taking place at depths not accessible for in situ observation. The drawback is the necessity to decipher a fossil record, where microstructures are not quenched but progressively reshaped in successive episodes at differing conditions throughout the geologic history - a demanding situation.

Laboratory experiments can be designed to simulate coseismic loading to high stress in the uppermost plastosphere. For this stage of rapid loading, strain rate and stresses attained come close to those expected for natural deformation (Trepmann et al. 2007; Druiventak et al., 2012). Consequently, microfabrics developed in these experiments are expected to correspond to those formed in nature. Unfortunately, a direct comparison is precluded by the prolonged cooling history of metamorphic rocks exhumed over millions of years. During that part of the history, microfabrics developed at coseismic loading are progressively modified in the later course of the same cycle by creep at decaying stress. Moreover, overprinting of repeated cycles is very likely, blurring the original record.
To establish evidence for ancient stress cycles in the middle crust, induced by large earthquakes in the overlying schizosphere, it is necessary to identify microstructural indications of rapid coseismic loading to high stress, despite being necessarily overprinted during a prolonged period of creep during stress relaxation. In natural rocks, indicators for short-term deformation are for instance mechanical twinning (Trepmann and Stöckhert, 2001) or multiple fragmentation of strong brittle crystals embedded in a ductile matrix (Trepmann and Stöckhert, 2002; Le et al., 2005). In these cases, resulting characteristic microstructures are not destroyed by subsequent creep. For quartz the situation is more complicated, as microstructures created during quasi-instantaneous loading at temperatures above about $300^{\circ} \mathrm{C}$ are modified or entirely obliterated in the course of subsequent creep during stress relaxation (Trepmann and Stöckhert, 2003). Laboratory experiments designed to explore the effects of such overprint require high temperatures, in order to speed up processes and to keep stresses at a level expected for nature.

To explore microstructures bearing potential for identification of an initial high-stress deformation event in rocks with a subsequent prolonged creep history, a set of experiments combining high-stress and low-stress deformation on natural vein quartz are performed. We follow the original concept of "kick and cook" experiments, designed to simulate coseismic loading and postseismic relaxation in the uppermost plastosphere (Trepmann et al., 2007; Druiventak et al., 2011, 2012). In this study, we replace the "cook" procedure, which denotes a stage of high temperature and nominally zero differential stress, by a more realistic "creep" stage at high temperature and moderate residual stress, during which microstructures created in the initial stage of high-stress deformation ("kick") become modified during further deformation. Microstructures created in kick and creep experiments in the laboratory are expected to represent the record of quartz acquired in the uppermost plastosphere in tectonically active regions of continental crust, and are probably preserved in many exhumed metamorphic rocks due to contemporary cooling. The goal is to identify microstructures still preserving evidence for an earlier coseismic stress peak, despite being modified during subsequent creep deformation at lower stress.

\section{Experimental procedures}

Triaxial deformation experiments on natural vein quartz were performed in a modified Griggs-type, servohydraulically controlled, solid-medium deformation apparatus (Rybacki, et al., 1998). Starting material is pure natural vein quartz (CR1; > 99.9\% quartz) with grain size of $\sim 1 \mathrm{~mm}$ and average dislocation density on the order of $10^{12} \mathrm{~m}^{-2}$, as described by Trepmann et al. (2007). Cylindrical samples with a length of $\sim 7 \mathrm{~mm}$ and a diameter of $\sim 3.7 \mathrm{~mm}$ are prepared by drilling. Platinum capsules are used with a wall thickness 
of $0.1 \mathrm{~mm}$ to prevent reaction between specimen and the surrounding pressure transmitting medium, which is a mixture of 65.5 mole \% $\mathrm{CsCl}$ and 34.5 mole $\% \mathrm{NaCl}$. Heating is provided by a graphite resistance furnace and temperature is measured by two thermocouples, placed close to the upper and lower end of the sample, respectively. The axial piston used is $4.7 \mathrm{~mm}$ in diameter. Piston movement is controlled using the signal of two displacement transducers.

The initial stage of high-stress deformation (kick) is performed at a temperature of $400^{\circ} \mathrm{C}$ and a confining pressure of $2.0 \mathrm{GPa}$. The axial force is increased up to $60-80 \mathrm{kN}$ by propagating the axial piston into the sample assembly with a constant velocity of $2.5-2.9 \mathrm{~mm} \mathrm{~h}^{-1}$, corresponding to a strain rate of about $10^{-4} \mathrm{~s}^{-1}$ for a sample length of 7-8 mm. For the subsequent stage of low-stress deformation (creep), the axial piston is first retracted to reduce remaining load on the sample to about $50 \mathrm{kN}$. Afterwards, temperature is raised to between $900^{\circ} \mathrm{C}$ and $1000^{\circ} \mathrm{C}$ at confining pressure of 2.5 or $2.7 \mathrm{GPa}$ (Table 1), the conditions being held for $16 \mathrm{~h}$. With respect to axial load, two different types of run are performed (Fig. 2c). In experiment CR1-13, the axial piston is advanced into the sample assembly with a rate of $0.07 \mathrm{~mm} \mathrm{~h}^{-1}$, keeping the load approximately constant. In experiments CR1-14 through CR1-17, the axial piston is not advanced and axial load decreases with time during creep deformation.

Temperature applied in kick experiments is similar to that expected in the upper plastosphere of continental crust, where coseismic stress changes during large earthquakes lead to quasi-instantaneous deformation. For the sake of a wellcontrolled experiment and protection of apparatus, strain rate is chosen somewhat lower compared to that expected for coseismic deformation, while confining pressure $\sigma_{2}=\sigma_{3}=$ $2 \mathrm{GPa}$ exceeds expected natural conditions by a factor of $>4$, which helps to suppress brittle failure. For the subsequent creep experiment, confining pressure is further increased in order to keep experimental conditions in the stability field of $\alpha$-quartz and to prevent melting of the confining medium. The creep experiment is designed to represent postseismic creep in the uppermost plastosphere. Temperatures of $900-1000^{\circ} \mathrm{C}$ are required to speed up creep accompanied by recovery and recrystallization, which otherwise would not be accessible on laboratory timescales. The trade temperature for rate is commonplace in experimental rock deformation, being the only way to achieve measurable deformation at stress levels corresponding to those prevailing in nature (e.g. Paterson, 1987, 1990; McLaren, 1991; Evans and Kohlstedt, 1995). For pure quartz aggregates, experimental deformation at high temperatures and high strain rates was demonstrated to yield microfabrics similar to natural rocks (e.g. Stöckhert et al., 1999; Hirth and Tullis 1992, 1994; Hirth et al., 2001; Stipp et al., 2002; Stipp and Tullis, 2003).
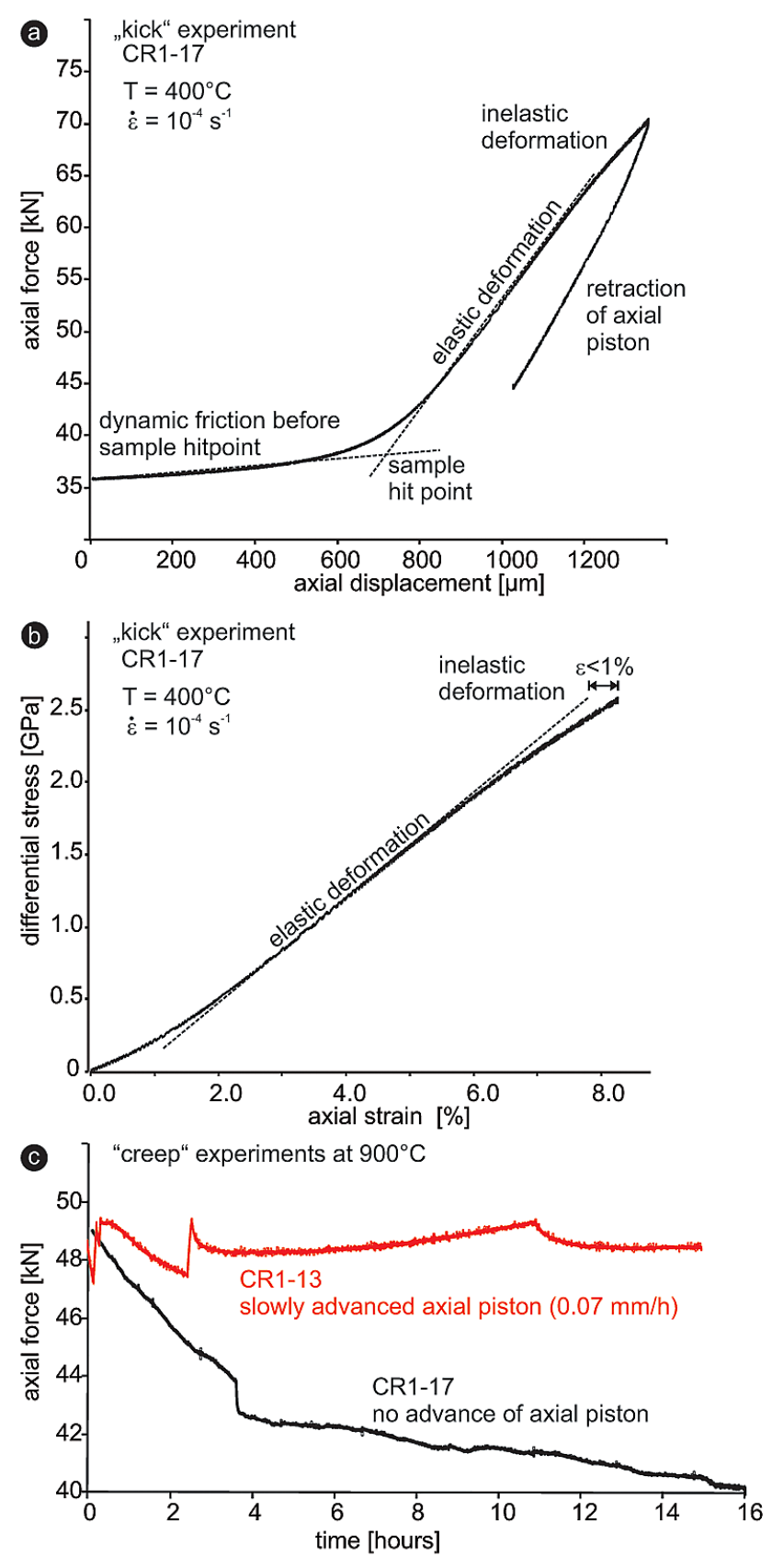

Fig. 2. (a) Selected force-time curve and (b) corresponding stressstrain curve for low-temperature, high-stress "kick" experiment CR1-3. (c) Selected force-time curves for high-temperature, lowstress ("creep") stage in the experiments CR1-13 (stress kept approximately constant by moving the piston into the sample assembly) and CR1-17 (stress relaxation, no active movement of piston).

\section{Analytical methods}

Polished thin sections $(\sim 30 \mu \mathrm{m})$ were prepared from the experimentally deformed samples, cut parallel to the cylinder axis, and used for microstructural analysis by polarization and scanning electron microscopy (SEM). Crystallographic 
Table 1. Experimental data.

\begin{tabular}{|c|c|c|c|c|c|c|c|c|c|c|c|c|c|}
\hline \multirow[t]{2}{*}{ Sample } & \multicolumn{6}{|c|}{ High-stress deformation "Kick" } & \multicolumn{6}{|c|}{ Low-stress deformation at high temperature "Creep" } & \multirow[b]{2}{*}{$\begin{array}{l}\varepsilon_{\text {tot }} \\
{[\%]}\end{array}$} \\
\hline & $\begin{array}{c}P_{\text {conf }} \\
{[\mathrm{GPa}]}\end{array}$ & $\begin{array}{c}T_{\mathrm{nom}} \\
{\left[{ }^{\circ} \mathrm{C}\right]}\end{array}$ & $\begin{array}{r}T_{\text {meas }} \\
{\left[{ }^{\circ} \mathrm{C}\right]}\end{array}$ & $\begin{array}{c}\mathrm{d} \varepsilon / \mathrm{d} t \\
{\left[\mathrm{~s}^{-1}\right]}\end{array}$ & $\begin{array}{r}\Delta \sigma_{\max } \\
{[\mathrm{GPa}]}\end{array}$ & $\begin{array}{r}\varepsilon_{1} \\
{[\%]}\end{array}$ & $\begin{array}{c}P_{\text {conf }} \\
{[\mathrm{GPa}]}\end{array}$ & $\begin{array}{c}T_{\text {nom }} \\
{\left[{ }^{\circ} \mathrm{C}\right]}\end{array}$ & $\begin{array}{r}T_{\text {meas }} \\
{\left[{ }^{\circ} \mathrm{C}\right]}\end{array}$ & $\begin{array}{c}\mathrm{d} \varepsilon / \mathrm{d} t \\
{\left[\mathrm{~s}^{-1}\right]}\end{array}$ & $\begin{array}{r}\Delta \sigma_{\max } \\
{[\mathrm{MPa}]}\end{array}$ & $\begin{array}{r}\varepsilon_{\text {tot }}-\varepsilon_{1} \\
{[\%]}\end{array}$ & \\
\hline CR1-1 & 2 & 400 & 400 & $10^{-4}$ & 3.3 & 2 & - & - & & - & - & & 2 \\
\hline CR1-3 & 2 & 400 & 396 & $10^{-4}$ & 3.2 & 2 & - & - & & - & - & & 2 \\
\hline CR1-13 & 2 & 400 & 402 & $10^{-4}$ & 3.4 & 3 & 2.5 & 900 & 913 & $1.8 \times 10^{-6}$ & 254 & 10 & 13 \\
\hline CR1-14 & 2 & 400 & $*$ & $10^{-4}$ & 3.2 & 2 & 2.5 & 950 & $*$ & $0.5 \times 10^{-6}$ & 140 & 2.5 & 4.5 \\
\hline CR1-15 & 2 & 400 & $*$ & $10^{-4}$ & 1.2 & $<1$ & 2.7 & 1000 & $*$ & $1.1 \times 10^{-6}$ & 152 & $\sim 6$ & 6.5 \\
\hline CR1-16 & 2 & 400 & 375 & $10^{-4}$ & 3.0 & n.n. & 2.5 & 900 & 860 & $0.2 \times 10^{-6}$ & 125 & $\sim 1$ & 1.5 \\
\hline CR1-17 & 2 & 400 & 420 & $10^{-4}$ & 2.5 & $<1$ & 2.5 & 900 & 902 & $0.2 \times 10^{-6}$ & 125 & $\sim 1$ & 1.4 \\
\hline
\end{tabular}

$P_{\text {conf }}, \Delta \sigma_{\max }, \varepsilon_{1}$, and $\mathrm{d} \varepsilon / \mathrm{d} t$ denote confining pressure $\left(\sigma_{2}=\sigma_{3}\right)$, maximum differential stress attained, axial strain, and average strain rate, respectively. $T_{\text {nom }}$ denotes nominal temperature read out at thermocouple used for controlling, and $T_{\text {meas }}$ temperature measured at second thermocouple, which failed in two experiments $(*)$. Temperatures are not corrected for pressure. In the creep stage of experiment CR1-13, the axial piston was moved into the sample assembly to hold the load approximately constant, whereas in the other creep experiments the piston was not moved and stresses decreased with time (Fig. 1). See text for details.

orientation and microfabric of quartz were analysed by electron backscatter diffraction (EBSD) using a LEO 1530 scanning electron microscope. For indexing and processing of the data, the Oxford Instruments HKL software CHANNEL 5 was used. Crystallographic preferred orientations (CPO) are displayed as stereographic projections of the lower hemisphere.

Arrangement and density of dislocations in quartz were examined by transmission electron microscopy (TEM), using a Philips EM301 transmission electron microscope operated at $100 \mathrm{kV}$. TEM foils were prepared by the focussed ion beam (FIB) technique with a FEI Quanta200 3D instrument. All diffraction contrast images were obtained at bright field conditions. Dislocation densities $\rho$ are derived from TEM micrographs by counting the number of dislocation lines $(N)$ intersecting a unit area $(A)$ with $\rho=2 N / A$ (Karato, 2008).

\section{Mechanical data}

For the high-stress deformation (kick) experiment, forcedisplacement data were transformed into stress-strain curves (Fig. 2a and b), applying corrections for friction between axial piston and parts of the sample assemblage, as described by Trepmann et al. (2007). After reaching the elastic limit, stress increases with increasing strain in a non-linear manner, reflecting inelastic deformation with work hardening. Distinct stress drops are not observed. Maximum differential stress attained in the experiments is between 1.2 and $3.5 \mathrm{GPa}$. According to the stress-strain curves (Fig. 2b, Table 1), axial strain $\left(\varepsilon_{1}\right)$ accumulated during the kick stage of the experiments remains well below $3 \%$. The total sample strain $\left(\varepsilon_{\text {tot }}\right)$ attained after kick and creep experiments is determined by comparing the length of the quartz cylinder before and after deformation. It amounts to between 1.4 and $6.5 \%$ (Table 1) for experiments CR1-14 through CR1-17 with stress relaxation, and $13 \%$ for experiment CR1-13, where the piston was advanced slowly $\left(0.07 \mathrm{~mm} \mathrm{~h}^{-1}\right)$ into the sample assembly holding the stress level approximately constant. Cracks perpendicular to the cylinder axis resulting from unloading (e.g. Fitz Gerald et al., 1991; Stünitz et al., 2003) transect the entire sample and cause underestimation of total sample strain determined from the change in length of cylinder axis during the experiment. For the creep stage, approximate strain rates are estimated by dividing strain $\left(\varepsilon_{\text {tot }}-\varepsilon_{1}\right)$ by duration. Strain rates obtained are between 0.2 and $1.8 \times 10^{-6} \mathrm{~s}^{-1}$ (Table 1). Correction for friction, comparable to that used for the kick stage (Fig. 2), is not possible for the creep stage, because the piston is retracted after the deformation stage and subsequently confining pressure and temperature are increased. Therefore, reliable estimates of residual stress-driving deformation cannot be derived from stress-strain curves. Instead, differential stress is estimated from strain rate, using an experimental flow law for dislocation creep of quartz (Paterson and Luan, 1990). For given temperatures of 900 to $1000{ }^{\circ} \mathrm{C}$ and strain rates on the order of $10^{-6} \mathrm{~s}^{-1}$, inferred differential stress effective during the creep stage is in the range of 125 to $250 \mathrm{MPa}$. In experiments CR1-14 through CR1-17, in which the piston was not moved during the creep stage, stresses decayed in the course of the experiment, and derived strain rates of 0.2 to $1.1 \times 10^{-6} \mathrm{~s}^{-1}$ represent average values. Consequently, in creep experiments CR1-14 through CR117 , differential stresses initially exceeded the nominal values of 125 to $150 \mathrm{MPa}$, and may have been similar to $250 \mathrm{MPa}$ as obtained for experiment CR1-13, where the piston was advanced to hold the stress level constant (Table 1).

\section{Microfabrics}

The microstructures observed after kick experiments serve as a reference for overprint during the following creep stage in kick and creep experiments (Table 1). After the kick experiment, samples show arrays of microcracks (Fig. 3). The 
length of individual microcracks is typically about $50 \mu \mathrm{m}$, their spacing about $25 \mu \mathrm{m}$ and they are oriented normal to the cylinder axis, i.e. normal to the major principal stress $\sigma_{1}$ during deformation. Given this orientation, which is the same as for cracks crosscutting the entire sample, they are likewise interpreted to result from unloading (e.g. Fitz Gerald et al., 1991; Stünitz et al., 2003). In contrast, these microcrack arrays are associated with domains that reveal a slight misorientation $<2^{\circ}$ with respect to the intact host, visible by slightly differing extinction in the polarization microscope, and confirmed by EBSD (Fig. 3). The change in crystallographic orientation is not progressive, as would be expected for overall bending of the crystal, but oscillating (Fig. 3b). Although relative misorientation revealed by EBSD analysis barely emerges from noise, the map displayed in Fig. 3b reveals that misorientation corresponds to the features observed by polarization microscopy. The domain boundaries are aligned approximately parallel to the (0001) plane of quartz (Fig. 3a). Within the domains shown in Figure 3a, tiny lamellae with a spacing of a few $\mu \mathrm{m}$ are oriented apparently parallel to $\{z\}$ rhombohedral planes, as indicated by the combination of polarization microscopy and EBSDdata. A second set of slightly more diffuse and wider lamellae with a wider spacing of about $15 \mu \mathrm{m}$ is apparently parallel to $\{r\}$ rhombohedral planes. On TEM scale, areas with these characteristic microcrack arrays and lamellar structures show a high density of tangled dislocations and domains of lower dislocation density (Fig. 4), resembling a cellular structure (i.e. dislocation-poor domains separated by poorly ordered dislocation walls) known from cold worked materials (e.g. Humphreys and Hatherly, 2004).

After kick and creep experiments with low total strain of $<10 \%$ (piston is not moved during creep, Table 1), the microstructure as observed by polarization microscopy is characterized by (1) pronounced short-wavelength undulatory extinction (SWUE), (2) distinct deformation bands, and (3) occurrence of new grains aligned along strings at variable angles to the shortening direction (Figs. 5-7). Quartz grains showing SWUE appear crinkly with narrow bands oscillating in crystallographic orientation. Misorientation angles are up to about $2^{\circ}$ (Figs. 5c, f and 6b, d). Spacing of these bands corresponds to their width, showing a wavelength of 10 to $20 \mu \mathrm{m}$ (Fig. 7a). In contrast to SWUE, distinct deformation bands are characterized by plane and subparallel boundaries, and by a higher misorientation angle of about 10 to $15^{\circ}$ (Fig. 6a, b and d). Their orientation appears to be parallel to prism planes. The diameter of new recrystallized grains aligned in strings is about 10 to $30 \mu \mathrm{m}$, as indicated by a combination of polarization microscopy and EBSD analysis (Fig. 7c). Some isolated grains situated along deformation bands have a roughly rectangular grain shape and a larger diameter of 50 to $200 \mu \mathrm{m}$ (Fig. 5b). The orientation of new grains is nearly random but can locally show some orientation relation to the deformed host (Fig. 7b-d). The proportion of recrystallized grains is highly variable due
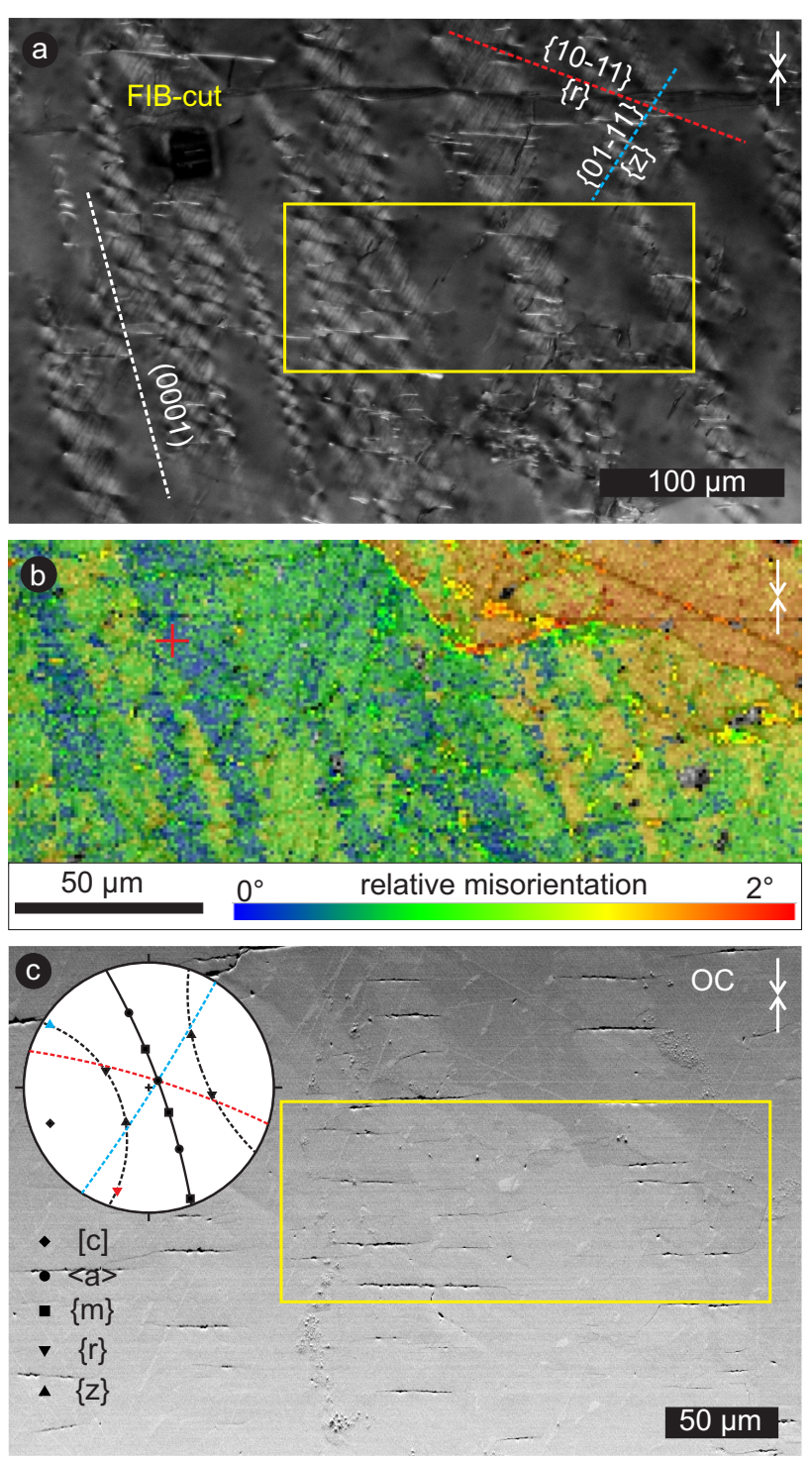

Fig. 3. Quartz microfabric after "kick" experiment CR-1-3 performed at $400^{\circ} \mathrm{C}, 2 \mathrm{GPa}$ confining pressure, and strain rate of $10^{-4} \mathrm{~s}^{-1}$. The shortening direction is vertical in all images, indicated by white arrows. (a) Polarized light micrograph showing slightly misoriented domains parallel (0001), containing arrays of microcracks and lamellae parallel to $\{r\}$ and $\{z\}$ rhombohedral planes. Location of EBSD map displayed in (b) is indicated by yellow rectangle. (b) EBSD map showing domains with misorientation relative to reference point (red cross); colours indicate misorientation, displayed as overlay on band contrast image in grey shades; non-coloured areas are not indexed. (c) Orientation contrast image of area shown in (a) and pole figure (lower hemisphere, equal angle) displaying crystallographic orientation. Location of the EBSD map shown in (b) is indicated by yellow rectangle.

to inhomogeneous deformation, reaching up to about $10 \%$ in samples CR1-14 through CR1-17, with moderate creep strain up to a few percent. For sample CR1-13, with creep 

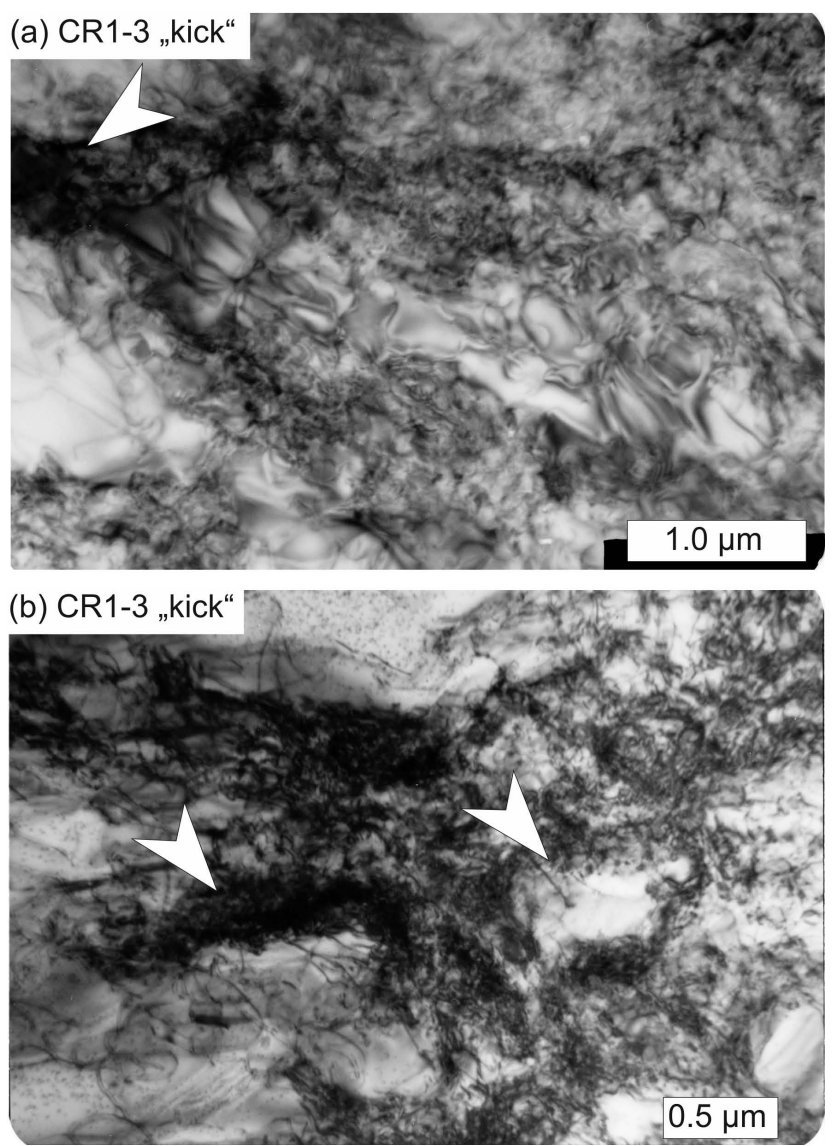

Fig. 4. TEM bright field micrographs of quartz from "kick" experiment $\mathrm{CR}-1-3$ performed at $400{ }^{\circ} \mathrm{C}, 2 \mathrm{GPa}$ confining pressure, and strain rate of $10^{-4} \mathrm{~s}^{-1}$, being exceedingly prone to radiation damage. (a, b) TEM micrographs from FIB cut foil located in Fig. 3a ("kick" experiment CR1-3). Quartz shows dislocation tangles and domains poor in dislocations bound by tangles and dislocation walls (arrows), referred to as cellular structure.

strain of $>10 \%$ (Table 1 ), recrystallized grains with a grain diameter of 20 to $30 \mu \mathrm{m}$ cover an area of about $40 \%$, being inhomogeneously distributed (Fig. 8). Large relict grains with a high Schmid factor for basal $\langle a\rangle$ glide reveal welldeveloped SWUE (Fig. 8b and c). Here, the orientation of SWUE is subparallel to $m$ prism planes (Fig. 8b). Recrystallized grains show a weak CPO, which is controlled by the crystallographic orientation of the remnant grains (Fig. 8e). Two of the $r$ rhombohedral planes are oriented preferentially in a plane perpendicular to the shortening direction, whereas the other $r$ rhombohedral plane is oriented parallel to the shortening direction, corresponding to the easy glide position for basal $\langle a\rangle$ glide (Fig. 8e). In places, recrystallized grains show a shape preferred orientation (SPO) with the long axes oriented in a plane perpendicular to the shortening direction (Fig. 8c).

In samples subject to kick and creep experiments, areas of quartz showing SWUE are characterized by dislocation densities on the order of $10^{12}$ to $10^{13} \mathrm{~m}^{-2}$ (Fig. 9). Dislocations are less tangled compared to kick experiments, but instead arranged in poorly ordered dislocation walls, separating domains with different diffraction contrast (Fig. 9a and b). These walls are lined up parallel to deformation lamellae observed by polarization microscopy. In contrast, in recrystallized grains dislocation density is very low (Fig. 9d).

\section{Discussion}

\subsection{Low-temperature plasticity}

According to the empirical Goetze's criterion (Evans and Kohlstedt, 1995), a material is expected to deform entirely by crystal-plastic mechanisms, when confining pressure exceeds differential stress. In the course of kick experiments carried out at a confining pressure of $2 \mathrm{GPa}$, differential stress is observed to increase to $>2 \mathrm{GPa}$ during progressive deformation (Fig. 2), with the exception of experiment CR 1-15 (Table 1). After initial glide-controlled deformation in the low-temperature plasticity regime, limited by strain hardening, the field of semi-brittle deformation is probably entered. For the earlier stage of deformation with strain hardening (Fig. 2), crystal-plastic deformation of quartz is expected to predominate at temperatures of $400{ }^{\circ} \mathrm{C}$ and strain rates of $10^{-4} \mathrm{~s}^{-1}$.

In the low-temperature plasticity field, crystal-plastic deformation of quartz is characteristically inhomogeneous, due to the limited number of activated glide systems (e.g. Paterson, 1969; Nicolas and Poirier, 1976; Paterson and Wong, 2005). In the polarization microscope, inhomogeneous deformation is reflected by undulatory extinction, domains with low oscillatory misorientation, and deformation lamellae, reflecting the presence of geometrically necessary dislocations (Nicolas and Poirier, 1976). On the TEM scale, a high density of tangled dislocations and a cellular structure (Fig. 4) are commonly observed after glide-controlled deformation in the low-temperature plasticity regime for various materials (e.g. Tsenn and Carter, 1987; Fredrich et al., 1989; Humphreys and Hatherly, 2004; Druiventak et al., 2011) including quartz (Morrison Smith et al., 1976; Carter et al., 1981; Hirth and Tullis, 1994). Tangled dislocations imply that glide becomes increasingly inhibited, giving rise to work hardening (e.g. Nicolas and Poirier, 1976; Humphreys and Hatherly, 2004; Durinck, et al., 2007) as observed for kick experiments (Fig. 3).

The domains with microcrack arrays up to about $50 \mu \mathrm{m}$ wide formed in kick experiments show boundaries perpendicular to the $c$ axis, parallel to the (0001) plane of quartz (Fig. 3), comparable to commonly observed sub-basal deformation lamellae in quartz (e.g. McLaren et al., 1970; McLaren and Hobbs, 1972; White, 1973, 1975; Christie and Ardell, 1974; Drury, 1993). Also, the characteristic oscillating microstructure with misorientation angles of $<2^{\circ}$ and 

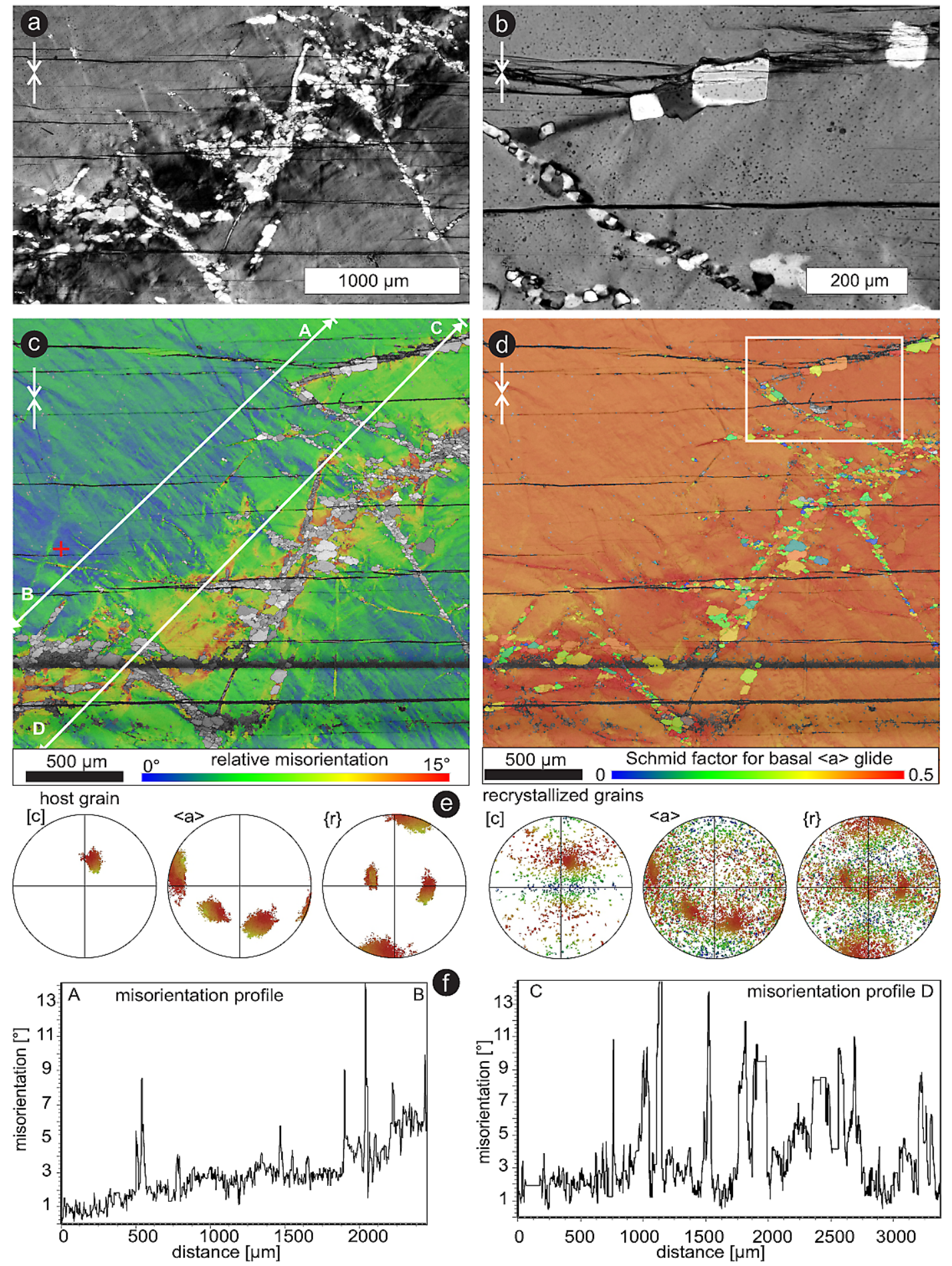

Fig. 5. Quartz microfabric after "kick and creep" experiment CR1-16, initially deformed at $400^{\circ} \mathrm{C}, 2 \mathrm{GPa}$ confining pressure, strain rate $10^{-4} \mathrm{~s}^{-1}$, and afterwards at $900^{\circ} \mathrm{C}, 2.5 \mathrm{GPa}$ confining pressure, undergoing stress relaxation. The shortening direction is indicated by white arrows. (a, b) Polarized light micrographs showing bands of recrystallized grains and pronounced SWUE. (c) EBSD map showing misorientation relative to reference point (red cross); colours indicate relative misorientation, displayed as overlay on band contrast image in grey shades; non-coloured areas are not indexed. White lines indicate location of misorientation profiles shown in (f). (d) EBSD map showing Schmid factor for basal $<\mathrm{a}>$ glide. White rectangle indicates location of polarized light micrograph in (b). (e) Pole figures showing crystallographic orientation of host grain and recrystallized grains, respectively. (f) Misorientation relative to first points (A and C) along white lines displayed in (b). 

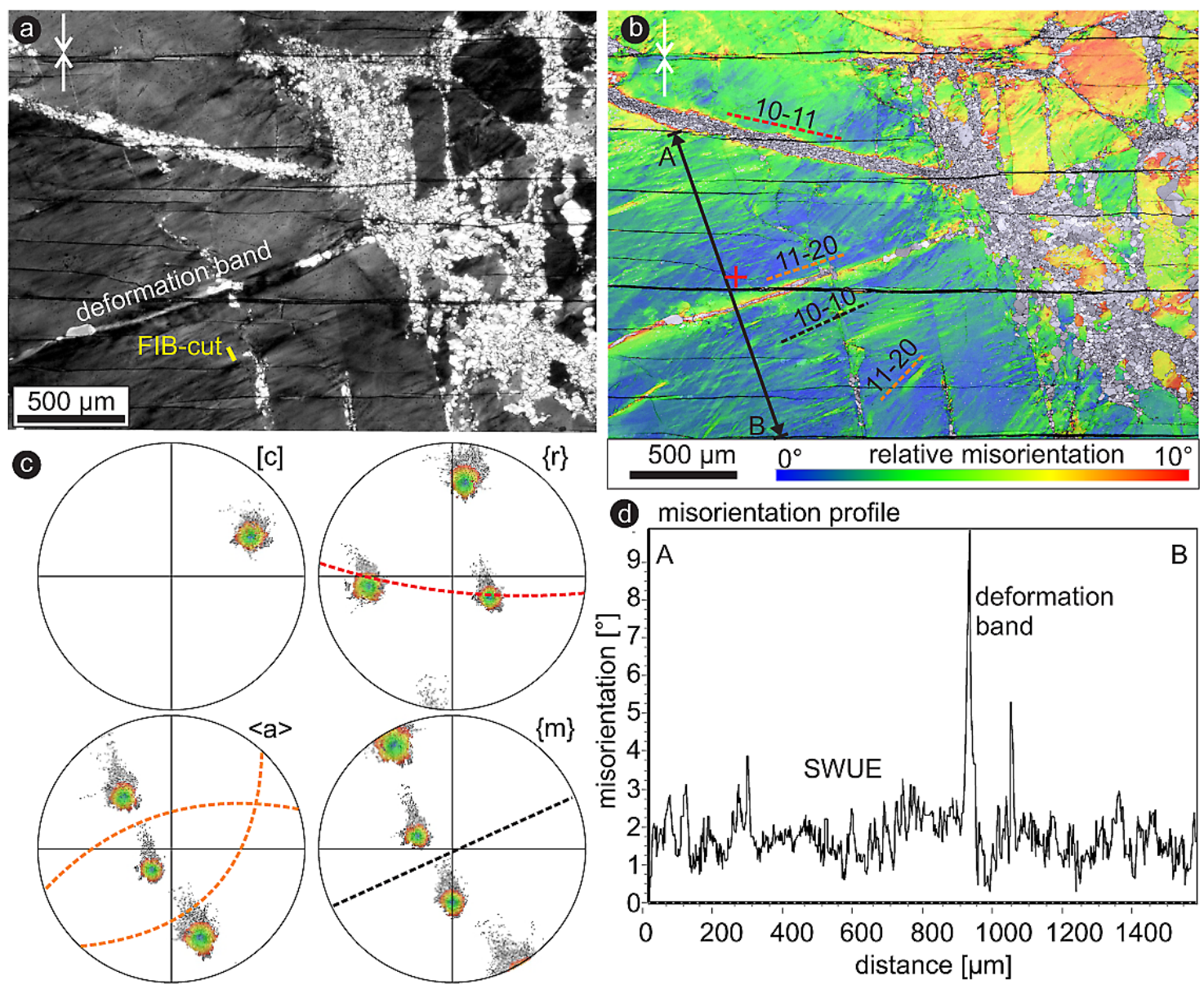

Fig. 6. Quartz microfabric after "kick and creep" experiment CR1-17, initially deformed at $400^{\circ} \mathrm{C}, 2 \mathrm{GPa}$ confining pressure, $10^{-4} \mathrm{~s}{ }^{-1}$ strain rate, and afterwards at $900^{\circ} \mathrm{C}, 2.5 \mathrm{GPa}$ confining pressure and approximately constant stress. The shortening direction is indicated by white arrows. (a) Polarized light micrograph showing strings of recrystallized grains, deformation bands and pervasive SWUE. Location of FIB cut TEM foil is marked by yellow rectangle. (b) EBSD map showing misorientation relative to reference point (red cross). Black line indicates location of misorientation profile displayed in (d). (c) Pole figures showing crystallographic orientation of host grain. Crystallographic planes, which are traced in (b), are indicated by great circles. (d) Misorientation relative to point A along yellow line displayed in (b).

the high density of tangled dislocations (Fig. 3) are similar. The sets of parallel microcracks confined to these domains (Fig. 3b) demonstrate that brittle failure is controlled by preceding crystal-plastic deformation. The tensile microcracks being oriented normal to the cylinder axis, i.e. normal to the maximum principal stress during the kick experiment, indicate that brittle failure occurred during unloading (Fitz Gerald et al., 1991; Stünitz et al., 2003). Nucleation of cracks is expected to be facilitated in regions that previously underwent strain hardening by pile-up of dislocations.

Similar deformation lamellae in olivine were observed by Druiventak et al. (2011) to form in deformation experiments at $600{ }^{\circ} \mathrm{C}$ on natural peridotites. In olivine, these lamellae are parallel to (100) and are associated with a high density of [001] screw dislocations. After deformation experiments at $300{ }^{\circ} \mathrm{C}$, instead fractures parallel (100) are observed with similar spacing as the deformation lamellae produced at $600^{\circ} \mathrm{C}$. The fractures were interpreted by Druiventak et al. (2011) to have developed as a consequence of hardening by pile-up of dislocations, whereas at $600^{\circ} \mathrm{C}$ crystal plastic deformation was more effective and stress concentration did not lead to brittle failure.

Within these sub-basal domains, two sets of narrow lamellae with slight misorientation are visible by polarization microscopy, oriented parallel to $\{r\}$ and $\{z\}$ rhombohedral planes. At low temperatures, the critical resolved shear stress for activation of $\langle a\rangle$ glide on rhombohedral planes exceeds that for basal $\langle a\rangle$ glide (Hobbs, 1968; 1985; Schmid and Casey, 1986; Kruhl, 1996; Heilbronner and Tullis, 2002). The sub-basal domains hosting lamellae parallel to $\{r\}$ and $\{z\}$ rhombohedral planes as observed by polarization microscopy suggest that differential stress attained during kick deformation was sufficient for simultaneous activation of both basal $\langle a\rangle$ and rhomb $\langle a\rangle$ glide systems. 


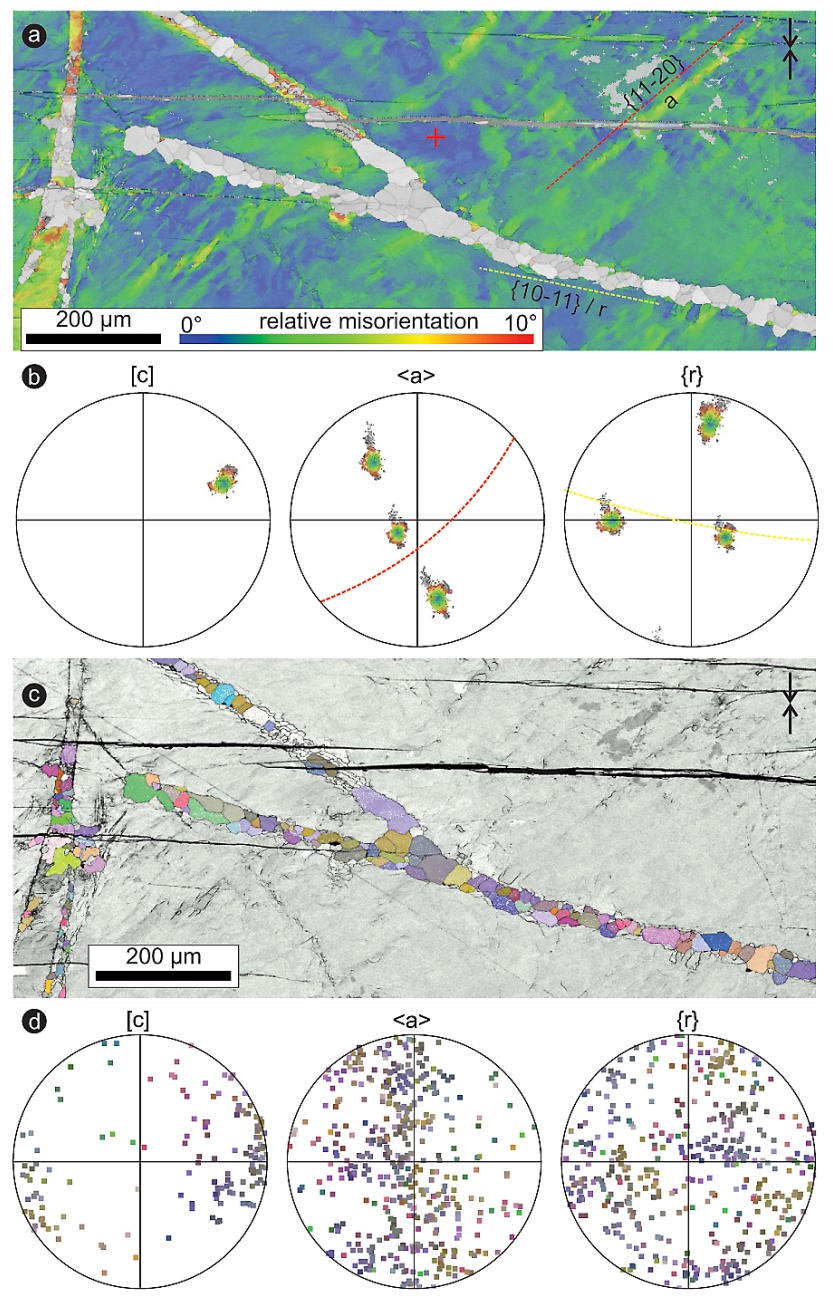

Fig. 7. SWUE and recrystallized quartz (grain size $17 \pm 9 \mu \mathrm{m}$ ) from "kick and creep" experiment CR1-17 initially deformed at $400^{\circ} \mathrm{C}$, $2 \mathrm{GPa}$ confining pressure, $10^{-4} \mathrm{~s}^{-1}$ strain rate, and afterwards at $900^{\circ} \mathrm{C}, 2.5 \mathrm{GPa}$ confining pressure and approximately constant stress. The shortening direction is indicated by black arrows. (a, b) EBSD map showing misorientation relative to reference point marked by red cross and corresponding pole figures. Orientation of \{a\} prism and $\{\mathrm{r}\}$ rhombohedral planes are displayed as traces in (a) and as great circles in (b). (c, d) EBSD map showing new grains, colour coding according to Euler angles corresponds to pole figures; crystallographic orientation of new grains is nearly random; orientation control by host grain is weak.

\subsection{Short-wavelength undulatory extinction - SWUE}

After kick and creep experiments, the microstructure is different from that developed after kick experiments. Microstructures reflecting deformation in the low-temperature plasticity field at high differential stress are modified by thermally activated processes taking place during the creep experiment. After experiments with total strain $<10 \%$ (Figs. 5-7), where the axial piston was not advanced during creep, SWUE is the prominent microstructural feature within preserved original grains discernible by polarization microscopy.

The appearance of SWUE differs in geometry and orientation from that of sub-basal deformation lamellae in quartz described by e.g. McLaren et al. (1970), McLaren and Hobbs (1972), White (1973, 1975), Christie and Ardell (1974), and Drury (1993), although the characteristic oscillating microstructure with misorientation angles of at best a few degrees is similar. Previous TEM investigations revealed that several submicroscopic structures can be associated with sub-basal deformation lamellae visible by polarization microscopy. The lamellae can be defined by arrays of elongate subgrains (McLaren and Hobbs, 1972; White, 1973; Blenkinsop and Drury, 1988; Drury, 1993; Trepmann and Stöckhert, 2003), bands of variable dislocation density, and planar arrays of fluid inclusions indicating crack healing (White, 1973, 1975; Christie and Ardell, 1974; White and Treagus, 1975; Drury, 1993) or localized precipitation of an aqueous phase (Wilkins and Barkas, 1978). Sub-basal deformation lamellae in quartz have been proposed to reflect glide-controlled deformation combined with dynamic recovery (McLaren and Hobbs, 1972; McLaren, 1991; Drury, 1993; Trepmann and Stöckhert, 2003; Vernooij and Langenhorst, 2005), being comparable with similar lamellae observed in metal alloys (Drury and Humphreys, 1986, 1987).

SWUE, as observed here (Figs. 5-8 and 11), has evolved by dynamic recovery during creep experiments from areas with a high defect density and tangled dislocations (Fig. 4), which had been produced by glide-controlled deformation in the low-temperature plasticity regime in the preceding kick experiment. The overprint results in SWUE with lamellar spacing on the order of $10 \mu \mathrm{m}$ and small oscillatory misorientation. In contrast, a pronounced SWUE in quartz was not observed in previous kick and cook experiments, which denotes high-stress deformation followed by isostatic annealing (Trepmann et al., 2007). This implies that SWUE is not produced during climb-controlled static recovery, but requires ongoing deformation including multiplication of dislocations and dynamic recovery.

Deformation bands parallel to prism planes are consistent with basal $\langle a\rangle$ glide predominating during creep (Fig. 6). Individual bands and lamellae are bound by less tangled dislocations, compared to microstructure developed after kick experiments, and dislocation walls including a share of geometrically necessary dislocations required for misorientation. As low-angle grain boundaries, such configurations are rather stationary and not prone to migration (Humphreys and Hatherly, 2004), spacing and misorientation being preserved while TEM scale microstructure is undergoing modification.

\subsection{Recrystallization}

Recrystallization is concurrent to recovery. During deformation at high temperatures, or during static annealing, both processes reducing dislocation density proceed side by side 

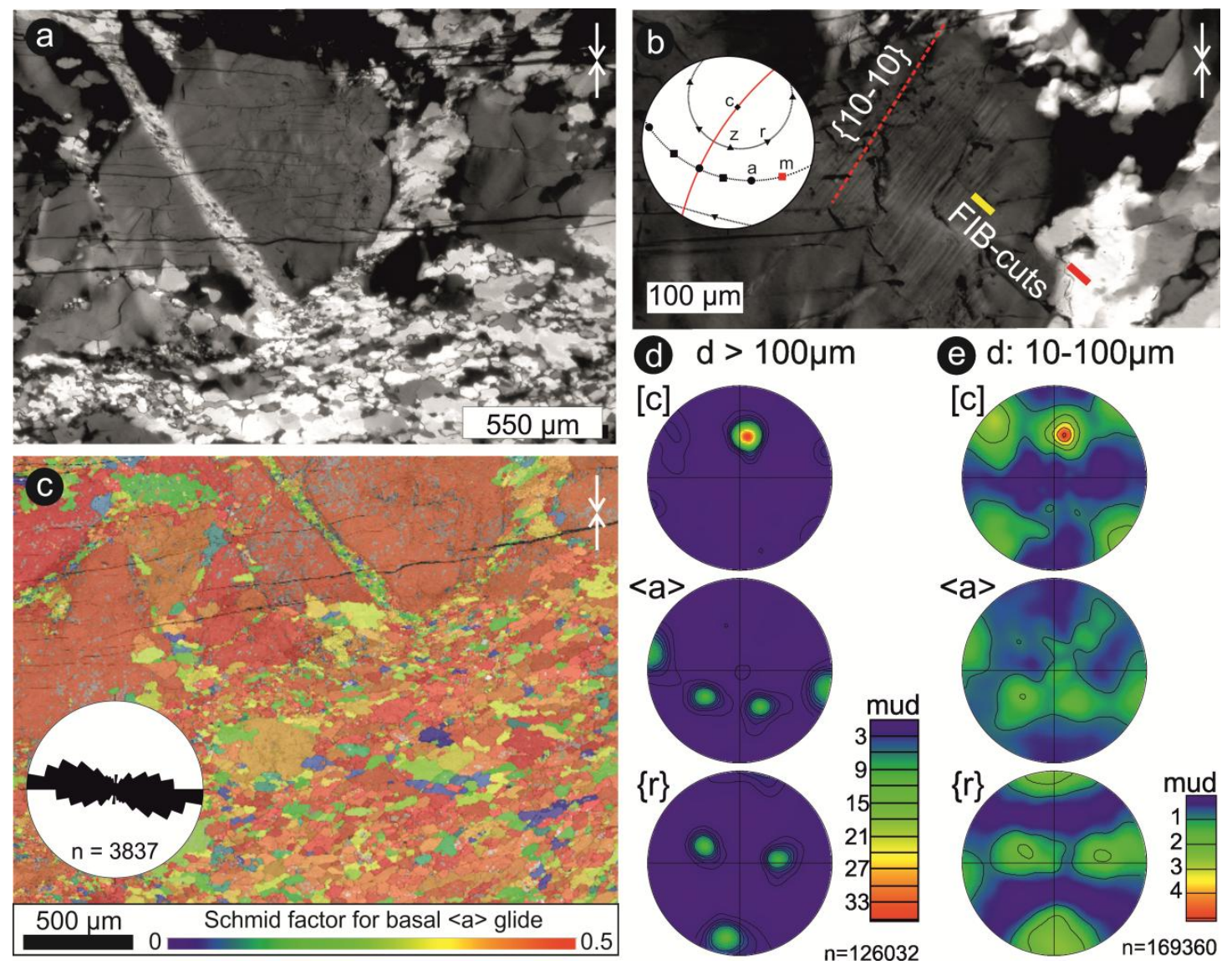

Fig. 8. Microfabric of quartz after "kick and creep" experiment CR1-13, initially deformed at $400{ }^{\circ} \mathrm{C}, 2 \mathrm{GPa}$ confining pressure, and strain rate of $10^{-4} \mathrm{~s}^{-1}$, and afterwards at $900^{\circ} \mathrm{C}, 2.5 \mathrm{GPa}$ confining pressure and approximately constant stress. The shortening direction is indicated by white arrows. (a) Polarized light micrograph showing partly recrystallized quartz. (b) Polarized light micrograph showing SWUE in large original quartz grain. Yellow and red lines mark locations of FIB cuts for TEM foils, from which bright field micrographs are shown in Fig. 9c and d, respectively. The crystallographic orientation of the main grain is shown by the pole figure. (c) EBSD map showing Schmid factor for basal $\langle a\rangle$ glide by colour code. (d, e) Pole figures (density plots) showing crystallographic orientation of grains with diameter larger than $100 \mu \mathrm{m}$ and of grains with diameters of $10-100 \mu \mathrm{m}$.

(e.g. Cotterill and Mould, 1976; Poirier, 1985; Humphreys and Hatherly, 2004). Recrystallization by formation and migration of high-angle grain boundaries seems to be more effective in highly strained zones, whereas recovery predominates elsewhere (e.g. Fitz Gerald and Stünitz, 1993; Trimby et al., 1998; Passchier and Trouw, 2008; Stipp and Kunze, 2008; Druiventak et al., 2012). Accordingly, zones of intense crystal-plastic deformation resulting from the kick experiment are replaced by small new grains during the creep experiment. These new grains are typically 10 to $20 \mu \mathrm{m}$ in diameter, forming strings of recrystallized grains, similar to those observed after the kick and cook experiments by Trepmann et al. (2007). In that earlier study, growth of new grains was inferred to have started from crystallites poor in dislocations, which had been formed by brittle comminution along cracks generated during the kick experiment. This interpretation is based on the observation that the new grains dis- play a nearly random crystallographic orientation, in most cases not related to the orientation of the deformed parental quartz. Reorientation of the small crystallites is envisaged to take place by rotation of tiny fragments along shear fractures, followed by formation and migration of mobile high-angle grain boundaries with high misorientation. Here, also a cellular structure characterized by defect-poor domains embedded in surroundings of high dislocation density is observed in deformed samples (Fig. 4b). Cells with high misorientation may act as seeds for the formation of new grains. Similar recrystallization microfabrics are described for olivine deformed in kick and cook experiments on peridotites (Druiventak et al. 2012) and for feldspar by Stünitz et al., 2003.

Whether old grains deformed in the kick experiment are replaced by new grains, or their internal structure resulting from inhomogeneous deformation evolves into SWUE by dynamic recovery, depends on strain accumulated during 


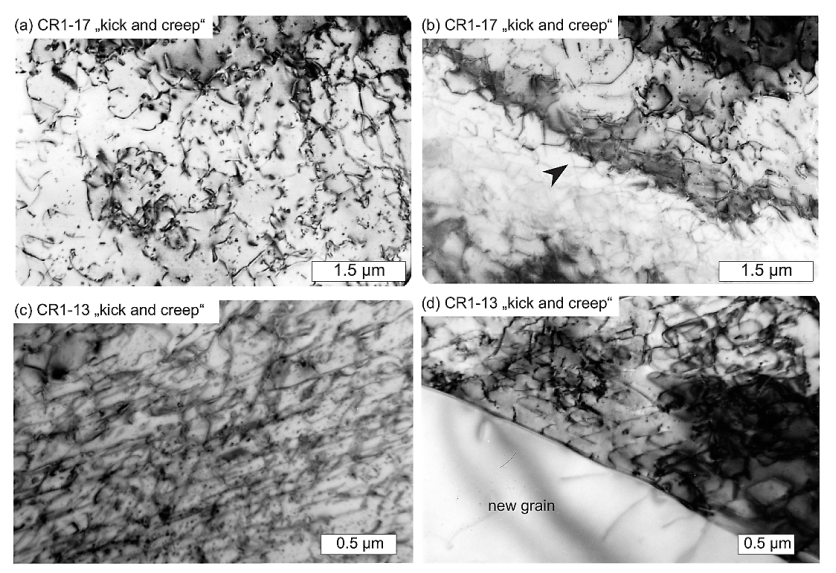

Fig. 9. TEM bright field micrographs of quartz, being exceedingly prone to radiation damage. (a, b) TEM micrographs from FIB cut foils shown in Fig. 6c; "kick and creep" experiment CR1-17 with stress relaxation. Quartz shows dislocation density on the order of $10^{12} \mathrm{~m}^{-2}$. Poorly ordered dislocation wall in (b) is marked by arrow. (c) TEM micrograph from FIB cut foil, location shown by yellow rectangle in Fig. 8b; "kick and creep" experiment CR1-13, with approximately constant stress. Quartz shows high density of dislocations arranged in walls parallel to SWUE visible by polarization microscopy. (d) TEM micrograph from FIB cut foil located by red rectangle in Fig. 8b; "kick and creep" experiment CR1-13, with approximately constant stress; high angle grain boundary between deformed and recrystallized grain with low dislocation density.

initial high-stress deformation. Where strain was concentrated, i.e. at sites where local brittle grain comminution occurred or at sites of extremely high dislocation densities, new grains developed. In contrast, in areas of lower strain, dynamic recovery results in SWUE.

In creep experiment CR1-13, where the axial piston is further advanced into the sample assembly, with deformation at persistent differential stresses of about $250 \mathrm{MPa}$ and accumulated strain of about $13 \%$, the original coarse-grained quartz is largely recrystallized. Preserved large original grains in between recrystallized grains commonly have a high Schmid factor for basal $\langle a\rangle$ glide, and these grains show welldeveloped SWUE (Fig. 8a and b). New grains show a very low dislocation density, whereas dislocation density in grains with SWUE is still as high as $10^{12}$ to $10^{13} \mathrm{~m}^{-2}$.

\subsection{Implications and comparison to natural microstructures}

SWUE requires a preceding stage of deformation at high stress in the low-temperature plasticity regime, whereas deformation bands can develop during continuous deformation by dislocation creep with dynamic recovery, gradually increasing misorientation. Accordingly, SWUE is interpreted to be characteristic for a sequence of (1) high-stress deformation with strain hardening, pile-up of dislocations, formation of cell structures, and locally brittle failure (as in ex-

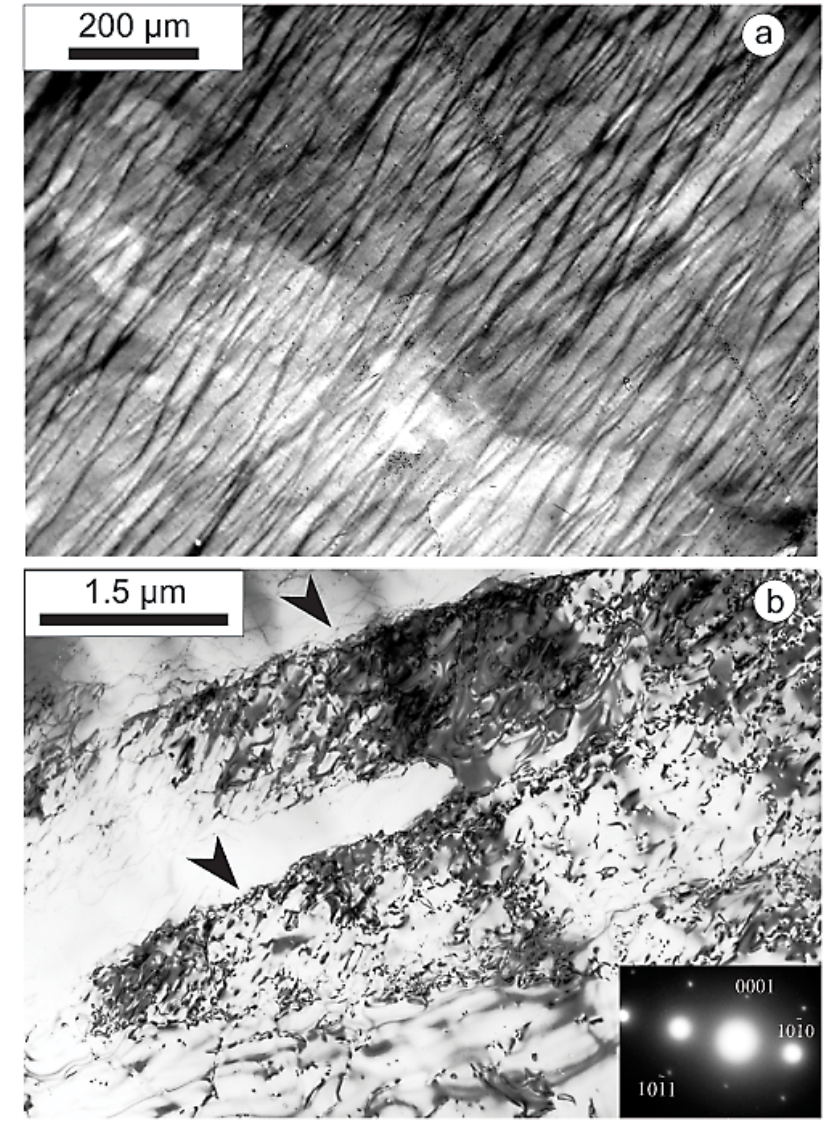

Fig. 10. Microstructures of naturally deformed vein quartz from St. Paul la Roche, France. (a) Polarized light micrograph showing pronounced SWUE. (b) TEM bright field micrographs of foil prepared by ion milling from region displayed in (a). Poorly ordered dislocation walls (arrows) confine domains with a width of about $1 \mu \mathrm{m}$, with dislocations being in or out of contrast at slightly different tilt, indicating differing crystallographic orientation. Dislocation density is on the order of $10^{13} \mathrm{~m}^{-2}$.

periments CR1-1 and CR1-3), and subsequent (2) creep at decaying stress with dynamic recovery (experiments CR114 to CR1-17). The generation of SWUE requires that only small strain was accumulated during both stages (1) and (2), for stage (1) probably limited by work hardening. If higher strain is accumulated during creep, as in experiment CR1-13 (Table 1), recrystallization becomes more effective and eliminates old grains.

In preserved old grains, SWUE is a sufficiently stable microstructure to keep the record of an earlier stage of deformation in the low-temperature plasticity regime, followed by dislocation creep at lower stress. As such, SWUE represents a valuable indicator for past seismic activity and stress cycles affecting the uppermost plastosphere. Moreover, SWUE suggests that stress relaxation was sufficiently fast to prevent prolonged creep with dynamic recrystallization, as otherwise 

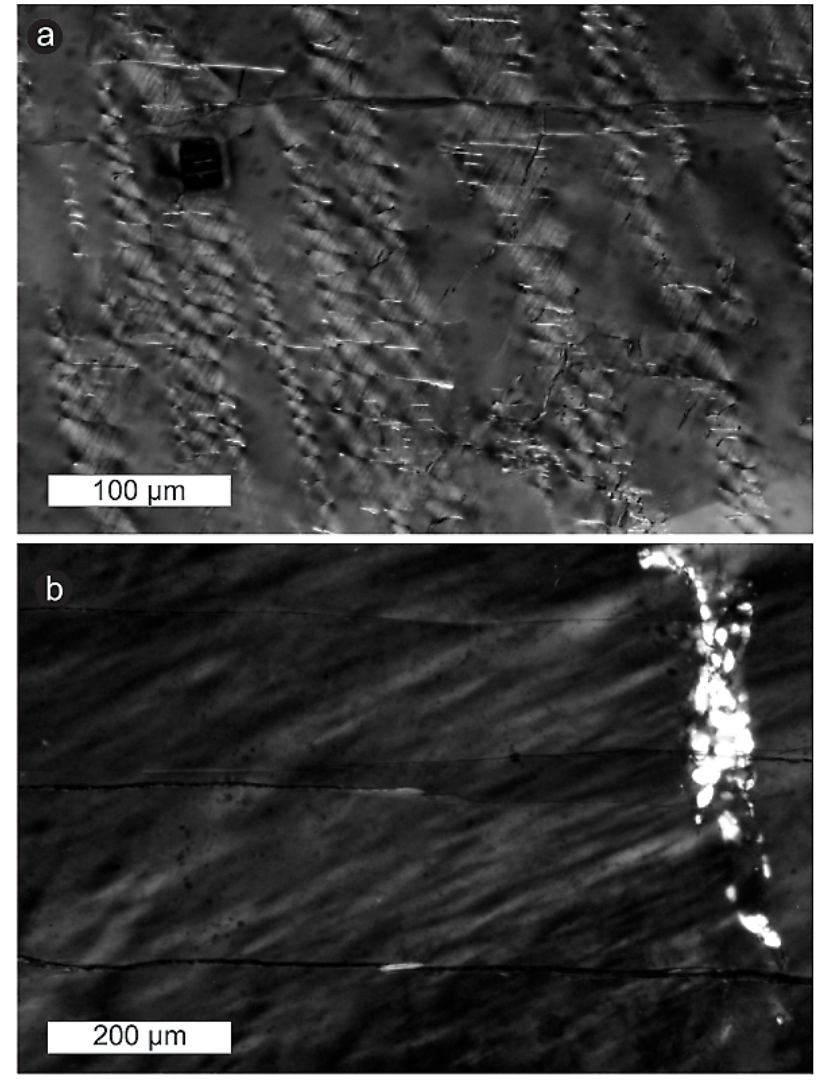

Fig. 11. Polarized light micrographs showing quartz microstructure after (a) "kick" experiment CR1-3 and (b) "kick and creep" experiment CR1-17. Note the different scale bar, which is chosen because of different characteristic wavelength of these microstructures. Microfabrics corresponding to (a) will not be observed in metamorphic rocks due to modification during prolonged cooling and exhumation history. Microfabrics depicted in (b) are similar to those found in exhumed metamorphic rocks (cf. Fig. 10) and indicate a stage of high-stress deformation in the low-temperature plasticity field, probably related to large earthquakes (see text).

respective grains would have been eliminated by recrystallization.

In natural rocks, pronounced SWUE has been observed in vein quartz from various localities, e.g. from St. Paul la Roche (Fig. 10, Trepmann, 2009), from Rugsundøya, Norway (Birtel and Stöckhert, 2008, their Fig. 7d), and from Evia, Greece (Nüchter and Stöckhert, 2007a, their Fig. 11e). Also, microstructures resembling SWUE in experimentally deformed quartz have been described in naturally deformed olivine from the Balmuccia peridotite complex (Matysiak and Trepmann, 2012, their Figs. 6d and 7a). These natural quartz and olivine microstructures occur in samples where microstructures are independently interpreted to reflect coseismic loading and postseismic stress relaxation in the uppermost plastosphere, near the lower tip of a seismically active fault.

\section{$7 \quad$ Summary and conclusions}

The main findings of our experiments are as follows:

1. Deformation of quartz in the low-temperature plasticity regime at high stress ("kick") results in broad domains and different sets of narrow lamellae, with misorientation angles $<2^{\circ}$ (Fig. 3). On TEM scale, these regions are characterized by a high density of tangled dislocations and a cellular structure (Fig. 4). Such microfabrics will not be observed in naturally deformed rocks, as they are modified during a prolonged cooling history.

2. During subsequent deformation at lower stress, these features evolve to a pronounced short-wavelength undulatory extinction (SWUE) by creep with dynamic recovery.

3. Shear zones with high strain accumulated during kick experiments are replaced by strings of recrystallized grains with a diameter of about 10 to $20 \mu \mathrm{m}$.

4. Prolonged creep at approximately constant stress increases the volume proportion of recrystallized grains. Large preserved original grains display a high Schmid factor for basal $\langle a\rangle$ glide and well-developed SWUE.

5. SWUE in quartz is proposed to represent a microfabric indicative of a stage of crystal-plastic deformation at high stress, which is sufficiently stable to be recognized in rocks with a prolonged subsequent creep deformation history.

6. As such, SWUE is proposed to record a stress history in the uppermost plastosphere related to past large earthquakes.

Acknowledgements. This study has been funded by the DFGCollaborative Research Centre 526. Constructive reviews by Luca Menegon and an anonymous referee are gratefully acknowledged.

Edited by: F. Rossetti

\section{References}

Ben-Zion, Y. and J. R. Rice: Dynamic simulations of slip on a smooth fault in an elastic solid, J. Geophys. Res., 102, 1777117784, doi:10.1029/97JB01341, 1997.

Ben-Zion, Y.: Collective behavior of earthquakes and faults: Continuum-discrete transitions, progressive evolutionary changes, and different dynamic regimes, Rev. Geophys., 46, RG4006, doi:10.1029/2008RG000260, 2008.

Ben-Zion, Y. and Lyakhovsky, V.: Analysis of aftershocks in a lithospheric model with seismogenic zone governed by damage rheology, Geophys. J. Int., 165, 197-210, 2006. 
Birtel, S. and Stöckhert, B.: Quartz veins record earthquake-related brittle failure and short term ductile flow in the deep crust, Tectonophysics, 457, 53-63, 2008.

Blenkinsop, T. G. and Drury, M. R.: Stress estimates and fault history from quartz microstructures, J. Struct. Geol., 10, 673-684, 1988.

Carter, N. L., Anderson, D. A., Hansen, F. D., and R. L. Kranz: Creep and creep rupture of granitic rocks, Geophys. Monogr. Ser., 24, 61-82, 1981.

Christie, J. M. and Ardell, A. J.: Substructures of Deformation Lamellae in Quartz, Geology, 2, 405-408, 1974.

Druiventak, A., Trepmann, C. A., Renner, J., and Hanke, K.: Low-temperature plasticity of olivine during high stress deformation of peridotite at lithospheric conditions - An experimental study, Earth Planet. Sci. Lett., 311, 199-211, doi:10.1016/j.epsl.2011.09.022, 2011.

Druiventak, A., Matysiak, A., Renner, J., and Trepmann, C. A.: Kick-and-cook experiments on peridotite: simulating coseismic deformation and post-seismic creep, Terra Nova, 24, 62-69, 2012.

Drury, M. R.: Deformation lamellae in metals and minerals, in: Defects and processes in the solid state: Geoscience applications: the McLaren volume edited by: Boland, J. N. and Fitzgerald, J. D., 195-212, 1993.

Drury, M. R. and Humphreys, F. J.: The development of microstructures in $\mathrm{Al}-5 \% \mathrm{Mg}$ during high temperature deformation, Acta Metal., 34, 2259-2271, 1986.

Drury, M. R. and Humphreys, F. J.: Deformation lamellae as indicator of stress level, EOS. Trans. Am. Geophys. Un., 44, 14711472, 1987.

Dunlap, W. J., Hirth, G., and Teyssier, C.: Thermomechanical evolution of a ductile duplex, Tectonics, 16, 983-1000, 1997.

Durinck, J., Devincre, B., Kubin, L., and Cordier, P.: Modelling the plastic deformation of olivine by dislocation dynamics simulations, Am. Mineral., 92, 1346-1357, 2007.

Ellis, S. and Stöckhert, B.: Elevated stresses and creep rates beneath the brittle-ductile transition caused by seismic faulting in the upper crust, J. Geophys. Res., 109, B05407, doi:10.1029/2003JB002744, 2004.

Evans, B. and Kohlstedt, D. L.: Rheology of rocks, in: Rock physics and phase relations - A handbook of physical constants, edited by: Ahrens, T. J., Ref. Shelf, Am. Geophys. Un., 3, 148-165, 1995.

Fitz Gerald, J. D. and Stünitz, H.: Deformation of granitoids at low metamorphic grades. I. Reactions and grain size reduction, Tectonophysics, 221, 269-297, 1993.

Fitz Gerald, J. D., Boland, J. N., McLaren, A. C., Ord, A., and Hobbs, B. E.: Microstructures in water-weakened single crystals of quartz, J. Geophys. Res., 96, 2139-2155, 1991.

Fredrich, J. T., Evans, B., and Wong, T.-f.: Micromechanics of the brittle to plastic transition in Carrara marble, J. Geophys. Res., 94, 4129-4145, 1989.

Heilbronner, R. and Tullis, J.: The effect of static annealing on microstructures and crystallographic preferred orientations of quartzites experimentally deformed in axial compression and shear, in: Deformation mechanisms, rheology and tectonics: Current status and future perspectives, edited by: de Meer, S., Drury, M. R., de Presser, J. H. P., and Panicky, G. M., Geological Society, London, Special Publications, 200, 191-218, 2002.
Hirth, G. and Tullis, J.: Dislocation creep regimes in quartz aggregates, J. Struct. Geol., 14, 145-159, 1992.

Hirth, G. and Tullis, J.: The brittle-plastic transition in experimentally deformed quartz aggregates, J. Geophys. Res., 99, 11, 73111, 748, 1994.

Hirth, G., Teyssier, C., and Dunlap, W. J.: An evaluation of quartzite flow laws based on comparisons between experimentally and naturally deformed rocks, Int. J. Earth Sci., 90, 77-87, 2001.

Hobbs, B. E.: Recrystallization of single crystals of quartz, Tectonophysics, 6, 353-401, 1968.

Hobbs, B. E.: The geological significance of microfabric analysis, in: Preferred orientation in deformed metals and rocks: An introduction to modern texture analysis, edited by: Wenk, H.-R., Academic Press, Orlando, Florida, 463-484, 1985.

Humphreys, F. J. and Hatherly, M.: Recrystallization and related annealing phenomena, Elsevier Ltd., Oxford, 2004.

Karato, S.-I.: Deformation of Earth materials: An introduction to the rheology of solid earth, Cambridge University Press, Cambridge, 2008.

Kruhl, J. H.: Prism- and basis-parallel subgrain boundaries in quartz: a micro-structural geothermobarometer, J. Metamorph. Geol., 14, 581-589, 1996.

Küster, M. and Stöckhert, B.: High differential stress and sublithostatic pore fluid pressure in the ductile regime - microstructural evidence for short term postseismic creep in the Sesia Zone, Western Alps, Tectonophysics, 303, 263-277, 1999.

Le, K. C., Korobeinik, M., and Hackl, K.: Estimation of crack density due to fragmentation of brittle ellipsoidal inhomogeneities embedded in a ductile matrix, Arch. Appl. Mech., 74, 439-448, 2005.

Matysiak, A. K. and Trepmann, C. A.: Crystal-plastic deformation and recrystallization of peridotite controlled by the seismic cycle, Tectonophysics, 530-531, 111-127, 2012.

McLaren, A. C.: Transmission electron microscopy of minerals and rocks. Cambridge University Press, New York, 1991.

McLaren, A. C. and Hobbs, B. E.: Transmission electron microscope investigation of some naturally deformed quartzites, in: Flow and Fracture of rocks, edited by: Heard, H. C., Borg, I. Y., Carter, N. C., Raleigh, C. B., Geophys. Monogr. 16, Am. Geophys. Union, 55-66, 1972.

McLaren, A. C., Turner, R. G., and Boland, J. N.: Dislocation structure of the deformation lamellae in synthetic quartz; a study by electron and optical microscopy, Contr. Mineral. Petr., 29, 101$115,1970$.

Morrison Smith, D. J., Paterson, M. S., and Hobbs, B. E.: An electron microscope study of plastic deformation in single crystals of synthetic quartz, Tectonophysics, 33, 43-97, 1976.

Nicolas, A. and Poirier, J. P.: Crystalline Plasticity and Solid State Flow in Metamorphic Rocks, Wiley-Interscience, London, 1976.

Nüchter, J. A. and Ellis, S.: Complex states of stress during the normal faulting seismic cycle: Role of midcrustal postseismic creep, J. Geophys. Res., 115, B12411, doi:10.1029/2010JB007557, 2010.

Nüchter, J. A. and Stöckhert, B.: Vein quartz microfabrics indicating progressive evolution of fractures into cavities during postseismic creep in the middle crust, J. Struct. Geol., 29, 1445-1462, 2007

Passchier, C. W. and Trouw, R. A. J.: Microtectonics, 2nd Edn., Springer Verlag, Berlin-Heidelberg-New York, 2008. 
Paterson, M. S.: The ductility of rocks, in: Physics of strength and plasticity, edited by: Argon, A. S., M.I.T. Press, Cambridge, Mass., 377-392, 1969.

Paterson, M. S.: Problems in the extrapolation of laboratory rheological data, Tectonophysics, 133, 33-43, 1987.

Paterson, M. S.: Rock deformation experimentation, Geophyscial Monograph Series, 56, 187-194, 1990.

Paterson, M. S. and Wong, T.-F.: Experimental rock deformation - the brittle field, 2nd Edn., Springer-Verlag, Berlin Heidelberg, 2005.

Rybacki, E., Renner, J., Konrad, K., Harbott, W., Rummel, F., and Stöckhert, B.: A Servohydraulically-controlled Deformation Apparatus for Rock Deformation under Conditions of Ultra-high Pressure Metamorphism, Pure Appl. Geophys., 152, 579-606, 1998.

Schmid, S. and Casey, M.: Complete fabric analysis of some commonly observed quartz c-axis patterns, Geophys. U. Geophys. Monogr., 36, 263-286, 1986.

Scholz, C. H.: The mechanics of earthquakes and faulting, 2nd Edn., Cambridge University press, Cambridge, 2002,

Stipp, M. and Kunze, K.: Dynamic recrystallization near the brittleplastic transition in naturally and experimentally deformed quartz aggregates, Tectonophysics, 448, 77-97, 2008.

Stipp, M., Stünitz, H., Heilbronner, R., and Schmid, S. M.: The eastern Tonale fault zone: a "natural laboratory" for crystal plastic deformation of quartz over a temperature range from 250 to $700{ }^{\circ}$ C, J. Struct. Geol., 24, 1861-1884, 2002.

Stöckhert, B., Brix, M. R., Kleinschrodt, R., Huford, A. J., and Wirth, R.: Thermochronometry and microstructures of quartz - a comparison with experimental flow laws and predictions on the temperature of the brittle-plastic-transition, J. Struct. Geo., 21, 351-369, 1999.

Stünitz, H., Fitz Gerald, J. D., and Tullis, J.: Dislocation generation, slip systems, and dynamic recrystallization in experimentally deformed plagioclase single crystals, Tectonophysics, 372, 215-233, 2003.

Trepmann, C. and Stöckhert, B.: Mechanical twinning of jadeite - an indication of synseismic loading beneath the brittle-ductile transition, Int. J. Earth Sci., 90, 4-13, 2001.
Trepmann, C. A.: Shock effects and pre-shock microstructures in hydrothermal quartz veins from the Rochechouart impact structure, France, J. Struct. Geol., 31, 1183-1196, 2009.

Trepmann, C. A. and Stöckhert, B.: Cataclastic deformation of garnet: A record of synseismic loading and postseismic creep, J. Struct. Geol., 24, 1845-1856, 2002.

Trepmann, C. A. and Stöckhert, B.: Quartz microstructures developed during non-steady state plastic flow at rapidly decaying stress and strain rate, J. Struct. Geol., 25, 2035-2051, 2003.

Trepmann, C. A., Stöckhert, B., Dorner, D., Küster, M., Röller, K., and Hamidzadeh Moghadam, R.: Simulating coseismic deformation of quartz in the middle crust and fabric evolution during postseismic stress relaxation - an experimental study, Tectonophysics, 442, 83-104, 2007.

Trimby, P. W., Prior, D. J., and Wheeler, J.: Grain boundary hierarchy development in a quartz mylonite, J. Struct. Geol., 20, 917 935, 1998.

Tse, S. T. and Rice, J. R.: Crustal earthquake instability in relation to the depth variation of frictional slip properties, J. Geophys. Res., 91, 9452-9472, 1986.

Tsenn, M.-C. and Carter N.-L.: Upper limits of power law creep of rocks, Tectonophysics, 136, 1-26, 1987.

Van Daalen, M., Heilbronner, R., and Kunze, K.: Orientation analysis of localized shear deformation in quartz fibres at the brittleductile transformation, Tectonophysics, 303, 83-107, 1999.

Vernooij, M. G. C., Kunze, K., and den Brok, B.: "Brittle" shear zones in experimentally deformed quartz single crystals, J. Struct. Geol., 28, 1292-1306, 2006.

White, S.: Deformation lamellae in naturally deformed quartz, Nat Phys. Sc., 245, 26-28, 1973.

White, S.: The effects of polyphase deformation on the intracrystalline defect structures of quartz. II. Origin of the defect structures, N. Jb. Miner. Abh., 123, 237-252, 1975.

White, S. and Treagus, J. E.: The effects of polyphase deformation on the intracrystalline defect structures of quartz. I. The defect structures, N. Jb. Miner. Abh., 123, 219-236, 1975.

Wilkins, R. W. T. and Barkas, J. P.: Fluid inclusions, deformation and recrystallisation in granite tectonites, Contrib. Mineral. Petr., 65, 293-299, 1978. 